\title{
G-quadruplex inducer/stabilizer pyridostatin targets SUB1 to promote cytotoxicity of a transplatinum complex
}

Yinzhu Hou, ${ }^{\text {a, b }}$ Tieliang Gan, ${ }^{\mathrm{b}}$ Tiantian Fang, ${ }^{\mathrm{a}}$ Yao Zhao, ${ }^{\text {a }}$ Qun Luo, ${ }^{\mathrm{a}, \mathrm{b}}$ Xingkai Liu, ${ }^{\mathrm{a}}$

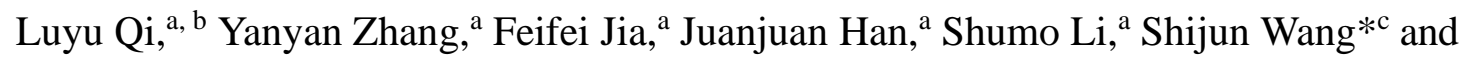
Fuyi Wang*a, b, c

a. Beijing National Laboratory for Molecular Sciences; CAS Key Laboratory of Analytical Chemistry for Living Biosystems; National Centre for Mass Spectrometry in Beijing, Institute of Chemistry, Chinese Academy of Sciences, No. 2 Zhongguancun North First Street, Haidian District, 100190 Beijing, P.R. China

b. College of Chemical Science, University of Chinese Academy of Sciences, Yuquan Road, Shijingshan District, 100049 Beijing, P.R. China

c. College of Traditional Chinese Medicine, Shandong University of Traditional Chinese Medicine, Jinshi Road, Lixia District, 250355 Jinan, P.R. China 


\begin{abstract}
Pyridostatin (PDS) is a well-known G-quadruplex (G4) inducer and stabilizer, yet its target genes have remained unclear. Herein, combining mass spectrometry based proteomics strategy with bioinformatics analysis, we revealed that PDS significantly downregulated 22 proteins, of which the genes contain rich G4 potential sequences, in HeLa cancer cells, consequently upregulating 16 proteins remarkably. The PDS-regulated proteins appeared to work synergistically to activate cyclin and cell cycle regulation, and to restrain the inhibition of ARE-mediated mRNA decay pathway, suggesting that PDS itself is not a potential anticancer agent, at least towards HeLa cancer. Importantly, among the PDS targeted genes, SUB1, which expresses the human positive cofactor and DNA lesion sensor PC4, was downregulated by 4.76 -fold. Further studies demonstrated that the downregulation of PC4 dramatically promoted the cytotoxicity of trans-[PtCl2(NH3)(thiazole)] towards HeLa cells to a similar level to that of cisplatin, contributable to retarding the repair of 1,3trans-platinated DNA lesion mediated by PC4. These findings not only provide new insights into better understanding on the biological functions of PDS, but also implicate a strategy for the rational design of novel multi-targeting platinum anticancer drugs via conjugation of PDS as a ligand to the coordination scaffold of transplatin for battling drug resistance to cisplatin.
\end{abstract}

Keywords: G-quadruplex; pyridostatin; gene targets; SUB1; proteomics; platinum; cytotoxicity 


\section{Introduction}

G-quadruplexes (G4s) are stable secondary structures of nucleic acids, formed by hydrogen bonding of guanine bases in G-rich DNA or RNA sequences. Although studies on the formation and distribution of specific G4s in human chromatin are debatable and even controversial, it is commonly accepted that there are over 10,000 G4 potential sequences in human chromatin. ${ }^{1-3} \mathrm{G} 4 \mathrm{~s}$ basically enrich in telomeres, somatic copy number alteration (SCNA) regions of cancer-associated genes and cancer genome genes. They were also widely detected in highly transcribed genes, especially regulatory regions such as promoters, splicing sites and 5'-untranslated regions (UTR). ${ }^{4,5}$ Since there are rich G4 potential sequences in oncogenes, e.g. $K R S,{ }^{6,7} c-M y b,{ }^{8} c-k i t,{ }^{9} B C L 2,{ }^{10} c-m y c,,{ }^{11,}{ }^{12}$ and $S R C,{ }^{1}$ G4s may serve as cancer biomarkers and be potential therapeutic targets. A number of G4 stabilizers, such as pyridostatin, ${ }^{13}$ Phen-DC3,${ }^{14}$ and BRACO $19,{ }^{15}$ have been shown to be able to trigger the formation of DNA double-strand breaks (DSBs), resulting in activation of the DNA repair pathway. ${ }^{16,17}$ These implicate that G4 stabilizers may be used for cancer treatment, especially for the types of tumors which impair DNA damage repair system.

Pyridostatin (PDS) (Figure 1a) as a G4 inducer and stabilizer ${ }^{13}$ mainly acts on nucleotide chains and can sustain the loading forces produced by DNA and RNA polymerases. ${ }^{18}$ Thus, DNA or RNA polymerases cannot open G4s, which as a consequence causes DNA DSBs. Moreover, PDS induces functional telomere abnormalities, generates DNA damages at specific genomic targets and exhibits antiproliferative activity. ${ }^{16}$ Due to the specific interactions between PDS and G4 patterns, PDS has also been derived as a tool for G4 enrichment, sequencing ${ }^{19}$ and biological function research. ${ }^{20}$ However, to the best of our knowledge, the gene targets of PDS and the influence of PDS on genome-wide gene expression have been largely unexplored.

To this end, we herein used mass spectrometry (MS) based quantitative proteomics, which is widely applied to dissect molecular pathogenesis ${ }^{21}$ and discover 
drug targets, ${ }^{22}$ to decipher the gene targets of PDS from the view of gene expression. Combining bioinformatics analysis, we discovered that PDS mainly down-regulated the expression of RNA binding proteins involved in RNA/mRNA splicing in HeLa cancer cells, which in turn up-regulated cell cycle related proteins, as a consequence, restraining the inhibition of ARE-mediated mRNA decay pathway and activating cyclin and cell cycle regulation. Importantly, we demonstrated for the first time that PDS down-regulated the expression of human positive cofactor PC4, significantly promoting the cytotoxicity of trans-[ $\mathrm{PtCl}_{2}\left(\mathrm{NH}_{3}\right)($ thiazole)] (trans-PtTz) complex towards HeLa cells. The mechanism of this unique effect was further explored via molecular biological approaches and mass spectrometry analysis.

\section{Results}

\section{Fluorescence imaging of target genes of PDS}

Since telomeres contain a large number of rich G4 potential sequences which may be the target of PDS, we firstly applied confocal laser scanning microscopy (CLSM) to co-localize telomeres and G4s in signal cells to elucidate this hypothesis. We utilized the Cas9-SunTag technique combined with HA-tag immunostaining ${ }^{23}$ to image telomeres while visualizing $\mathrm{G} 4 \mathrm{~s}$ by using G-quadruplex antibodies $\mathrm{BG} 4^{24}$ in human HeLa cervical cancer cells in the absence and the presence of PDS. The repeating peptide array termed SunTag was genetically fused to the endonucleasedeficient Cas9 (dCas9) protein ${ }^{23}$ and recruited multi-copies of scFv-GCN4-GFP-HA tag to illuminate telomeres directed by telomere-specific guide RNA (gRNA). In the case, the superposition of BG4 signal and HA-Tag signal could judge whether and how many G4 structures co-localize with telomeres. As shown in Figure 1b, PDS induced formation of G4 in telomere regions, evidenced by the increased Pearson's correlation coefficient from 0.0743 to 0.186 between the fluorescence signals of telomere and G4 in the single cell. However, the statistic results based on more cells indicated that after PDS treatment, the co-localization ratio of telomere to total G4 decreased, though the co-localization ratio of G4 to telomere increased (Figure 1c). This indicated that more G4s formed on non-telomeric regions in the presence of PDS. 
In other words, PDS mainly targeted non-telomeric nucleic acid sequences, in consistent with previous reports. ${ }^{13,16}$ 
a

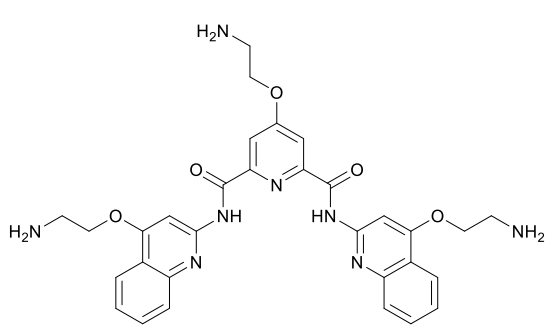

PDS

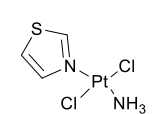

trans-PtTz

b
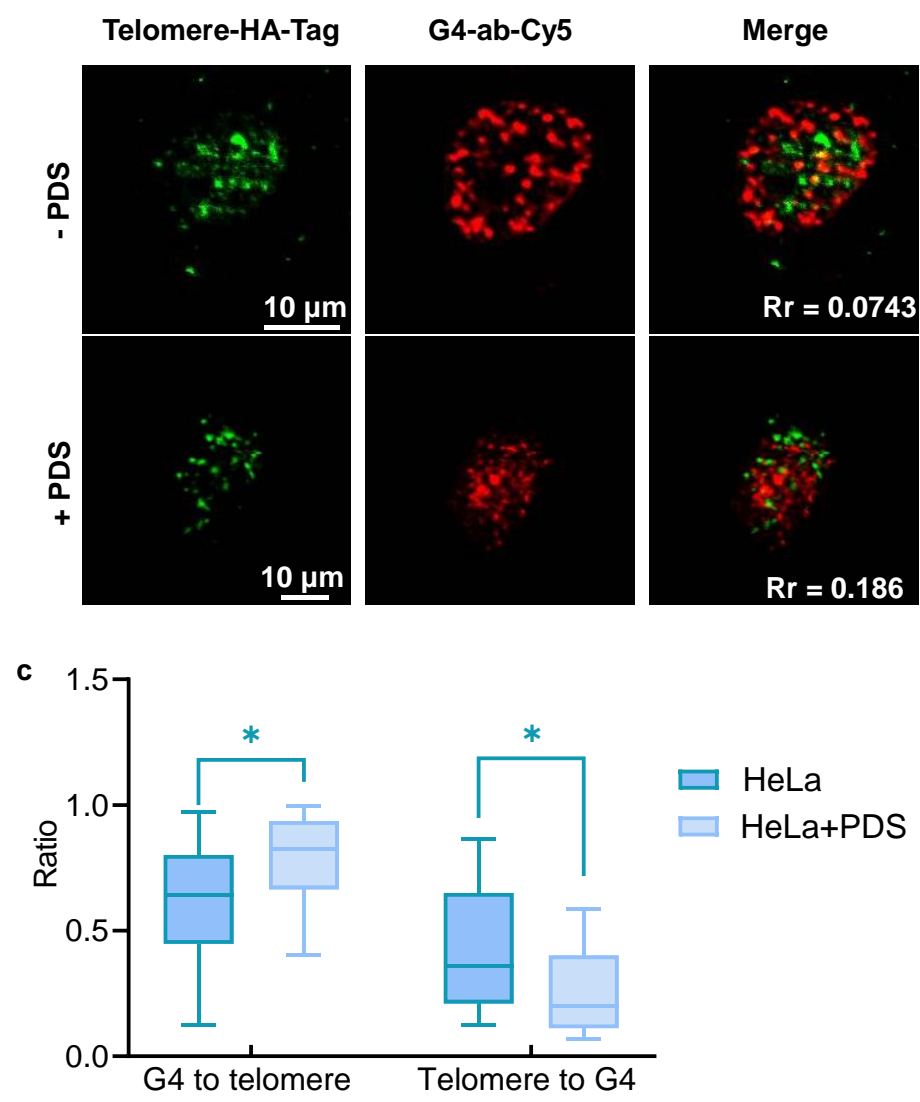

d

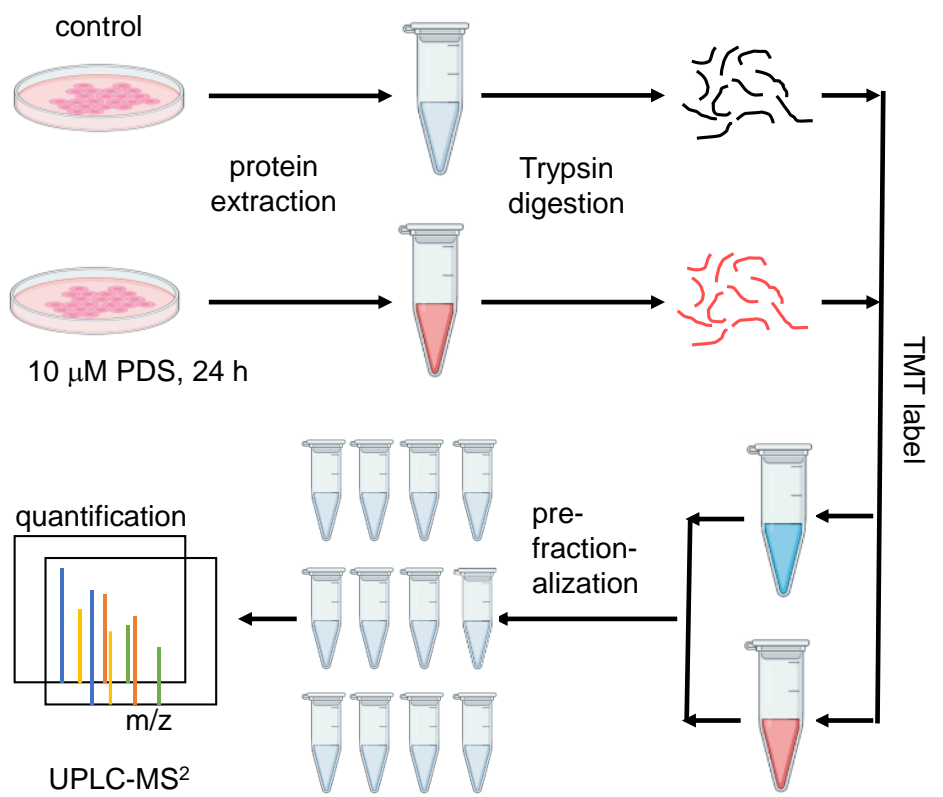

Figure 1. (a) The chemical structures of pyridostatin (PDS) and trans- 
[ $\mathrm{PtCl}_{2}\left(\mathrm{NH}_{3}\right)$ (thiazole)] (trans-PtTz). (b) Fluorescent co-localization of telomere and G4 DNA in HeLa cells transfected with Cas9-SunTag plasmids in the absence and the presence of PDS. Rr: Pearson's correlation coefficient; Green indicates telomeres labeled with HA-tag conjugated with Cas9-SunTag, $\lambda_{\mathrm{ex}}=488 \mathrm{~nm}, \lambda_{\mathrm{em}}=500 \mathrm{~nm}-600$ $\mathrm{nm}$; red indicates G4 immunofluorescence signal with G4 antibody BG4, $\lambda_{\mathrm{ex}}=635$ $\mathrm{nm}, \lambda_{\mathrm{em}}=650 \mathrm{~nm}-750 \mathrm{~nm}$. (c) Statistic chart of co-localization ratio of G4 to telomere or telomere to G4 in HeLa cells transfected with Cas9-SunTag plasmids in the absence and the presence of PDS. There were 16 cells in HeLa-control groups and 21 cells in HeLa+PDS group calculated for the co-localization ratio of G4 vs. telomere and telomere vs. G4. * indicates $\mathrm{p}<0.05$. (d) Workflow of mass spectrometric quantitative proteomics.

\section{Protein profiling of HeLa cells subject to PDS treatment}

Next, we applied mass spectrometry (MS) based quantitative proteomics to profile the protein expression of HeLa cells subject to PDS treatment (Fig. 1d). Three independent MS-based quantitation experiments on HeLa cells with and without 10 $\mu \mathrm{M}$ PDS treatment allowed us to identify a total of 4316 proteins (Figure 2a), of which 674 proteins have a statistical significance $(\mathrm{p}<0.05)$ (Figure 2b). The search results based on the MS/MS data are provided in Table S1 in the Electronic Supplementary Information. To identify the differentially expressed proteins (DEPs) in HeLa cells exposed to $10 \mu \mathrm{M}$ PDS for $24 \mathrm{~h}$, the protein profiles between two data sets were compared. We found that the abundance ratio (AR) of the 637 proteins expressing in the PDS treated group and the control group were between 0.667 and 1.50 , indicating that the expression of major proteins (637/674) was not significantly affected by PDS (Figure 2b). Notably, among the 674 proteins, only four proteins are directly related to telomere and their AR values were not significant changed, suggesting that PDS has little effect on the expression of telomere-related proteins, in consistent with the fluorescence co-localization results described above.

The fold change (FC), which is equal to AR of a protein expressing in PDS group 
vs control group when $A R>1$, but to negative reciprocal of $A R$ when $A R<1$, was used to describe how much a protein is up- or down-regulated. As shown in Figure S1 in the Supporting Information, 159 proteins were upregulated with FC $>1.2$, and 82 proteins downregulated with $\mathrm{FC}<-1.2$ in HeLa cells subject to PDS treatment. Among them, 22 proteins were significantly down-regulated, and 16 proteins remarkably upregulated with a $|\mathrm{FC}|>1.5$ (Figure 2c, d, Table $\mathrm{S} 2$ ).

As a G4 inducer and stabilizer, PDS is expected to down-regulate the expression of its targeted genes by inducing and sustaining formation of G4 structures. Thus, we applied Quadruplex forming G-Rich Sequences (QGRS) mapper ${ }^{25}$ in IPA program to count the potential G4 sequences in the 20 genes of which the expression was remarkably down-regulated by PDS. The results (Table 1) showed that all the target genes contain a significant number of potential G4 sequences in their transcribed sequences and promoter sequences. This proves that PDS down-regulated the expression of the target genes indeed via inducing G4 potential sequences in these genes to form stable G4s. It is worth pointing out that the gene TCOF1 simultaneously expresses treacle protein and its isoform 7, and the gene BCLAF1 does Bcl-2-associated transcription factor 1 and its isoform 3. However, the FC of each pair of proteins, resulting from PDS treatment were different from each other (Figure 2c, Table S2). 

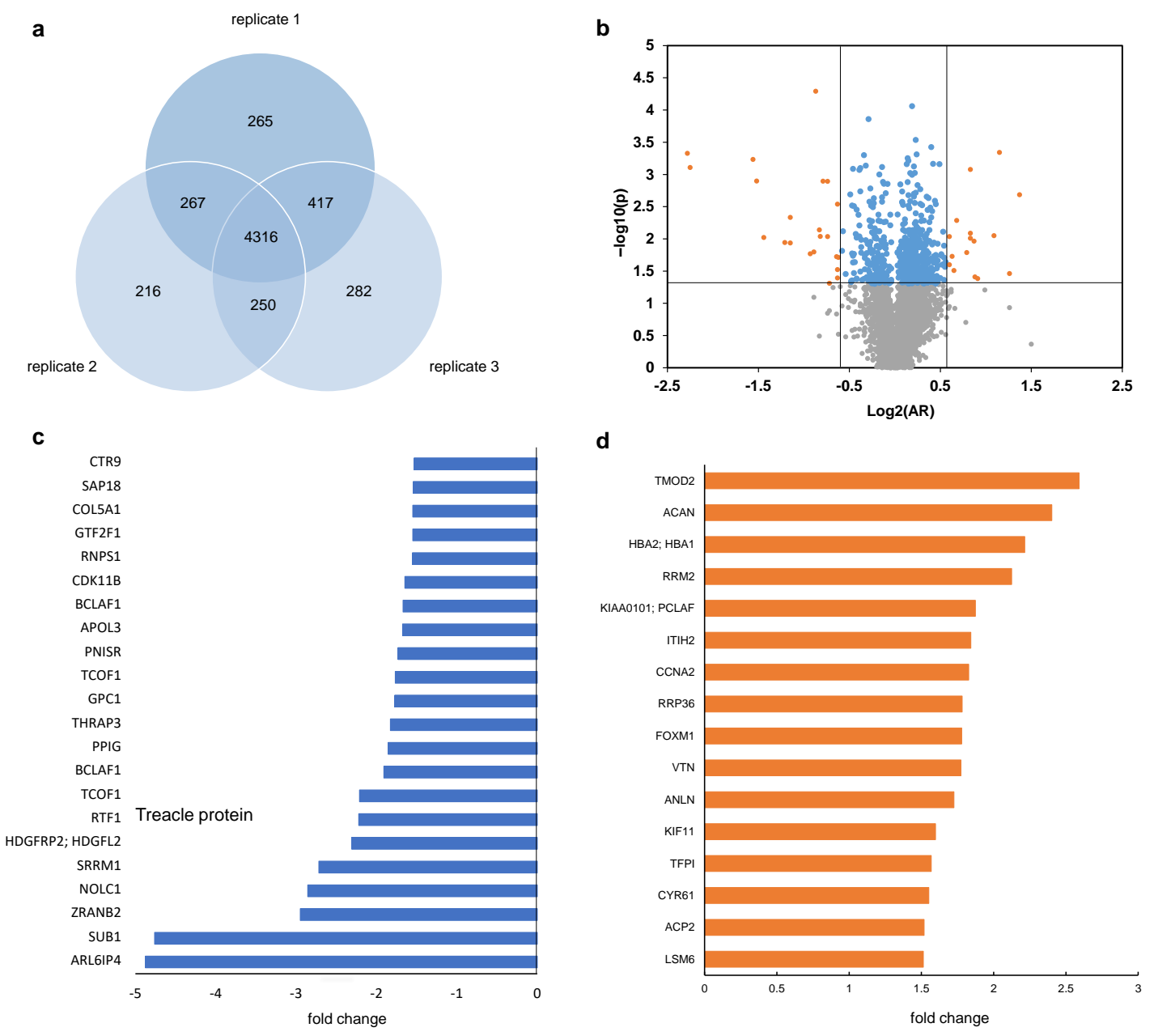

Figure 2. Quantitative proteomics analysis. (a) Venn diagram of the numbers of the proteins identified in three parallel experiments, showing 4316 proteins found in common. (b) Volcano map of the proteins commonly detected in three replicates. Gray represents proteins with $\mathrm{p}>0.05$, blue proteins with $\mathrm{p}<0.05$ and $0.667<$ abundance ratio $(\mathrm{AR})<1.50$, and orange proteins with $\mathrm{p}<0.05$, abundance ratio $<$ 0.667 or $>1.50$. (c, d) The significantly differential expressed proteins (DEPs) with change fold $<-1.5$ (c) or $>1.50$ (d) in HeLa cells subject to PDS treatment.

\section{Bioinformatics analysis of PDS regulated genes}

To understand the functions of proteins which were differentially expressed due to PDS treatment, we firstly performed bioinformatics analysis of the down-regulated proteins with $\mathrm{FC}<-1.5$ by IPA, but they were not enriched in certain signaling 
pathways (data not shown), though the gene ontology information summarized in Table S2 uncovered that most of the PDS-upregulated proteins are RNA binding proteins. Then we expanded the FC range of down-regulated proteins to $\mathrm{FC}<-1.2$ for IPA annotation. The results showed that the down-regulated proteins are mainly involved in cyclins and cell cycle regulation, cell cycle checkpoint control and G1/S checkpoint regulation, which are consistent with the biological functions of PDS reported previously. ${ }^{16}$ However, only a few $(3-4)$ genes (proteins) are related to each canonical pathway and no obvious activation or inhibition on the involved pathways by PDS was predicted (Figure 3a).

Similarly, we performed bioinformatics analysis on the PDS up-regulated proteins with FC $>1.2$ by IPA (Figure 3a). Surprisingly, the upregulated proteins were shown to activate the glioma invasiveness signaling significantly, and to restrain the inhibition of ARE-mediated mRNA degradation pathway. Interestingly, when we input all PDS down-regulated and up-regulated proteins with $|\mathrm{FC}|>1.2$ into IPA data pool for signaling pathway annotation, we found that apart from restraining the inhibition of the ARE-mediated mRNA degradation and activating the glioma invasiveness signaling, PDS were predicted to activate remarkably the cyclins and cell cycle regulation as well (Figure 3a). This is in line with previous report that PDS promoted cellular DNA replication unraveled by DNA fiber analysis. ${ }^{26}$

To further annotate the biological function of the PDS up-regulated proteins, of which the GO information was summarized in Table S2, we mapped the proteinprotein interaction (PPI) network of the 16 up-regulated proteins with $\mathrm{FC}>1.5$ by StringDB (Figure S2). We found that they were clustered into two groups by their biological functions: cellular component organization and regulation of cell cycle (Figure S2). The cellular component organization was triggered by the acute phase responses of cells to PDS stimulation, in which proteins ACAN, VTN, LSM6, RRP36, CYR61, TMOD2, ACP2 and HBA2 are involved. While RRM2, ANLN, CCNA2, FOXM1, KIF11 and KIAA0101 are related with the regulation of cell cycle. These are unexpected because PDS was thought to be able to induce the formation of G4s, 
mainly in the translation progresses, leading to formation of double-strand breaks (DSBs), which probably activated DNA-damage checkpoint signaling and cell cycle arrest. $^{16}$

To find out what resulted in the upregulation of cell cycle related proteins during the PDS treatment, the molecule activity predictor (MAP) simulation was performed in IPA program (Figure 3b). We found that the all PDS downregulated proteins with FC $<1.0$ led to the activation of three transcription factors: FOXO1, MITF and TP63, which subsequently upregulated the downstream proteins including ANLA, KIF11, CCNA2 and RRM2 (Figure 3b and Table S3) as well as FOXM1 and KIAA0101 which are co-expressed with the four cell cycle related proteins as shown in Figure S2. 
Table 1. The Quadruplex forming G-Rich Sequences (QSRS) in the genes of which the expression was significantly down-regulated by PDS.

\begin{tabular}{|c|c|c|c|c|c|c|c|c|c|c|}
\hline Gene Name & ARL6IP4 & $S U B 1$ & ZRANB2 & NOLCl & SRRMI & HDGFRP2 & $R T F 1$ & TCOF1 & $B C L A F 1$ & $P P I G$ \\
\hline QGRS in full gene sequence & 46 & 389 & 41 & 84 & 133 & 332 & 428 & 420 & 60 & 203 \\
\hline QGRS in promoter sequence & 28 & 11 & 9 & 17 & 22 & 8 & 15 & 8 & 6 & 11 \\
\hline Gene Name & THRAP3 & $G P C 1$ & PNISR & APOL3 & $C D K 11 B$ & RNPS1 & GTF2F1 & COL5A1 & SAP18 & CTR9 \\
\hline QGRS in full gene & 487 & 425 & 80 & 163 & 185 & 105 & 128 & 1958 & 57 & 119 \\
\hline QGRS in promoter sequence & 17 & 26 & 5 & 22 & 26 & 25 & 17 & 22 & 10 & 9 \\
\hline
\end{tabular}



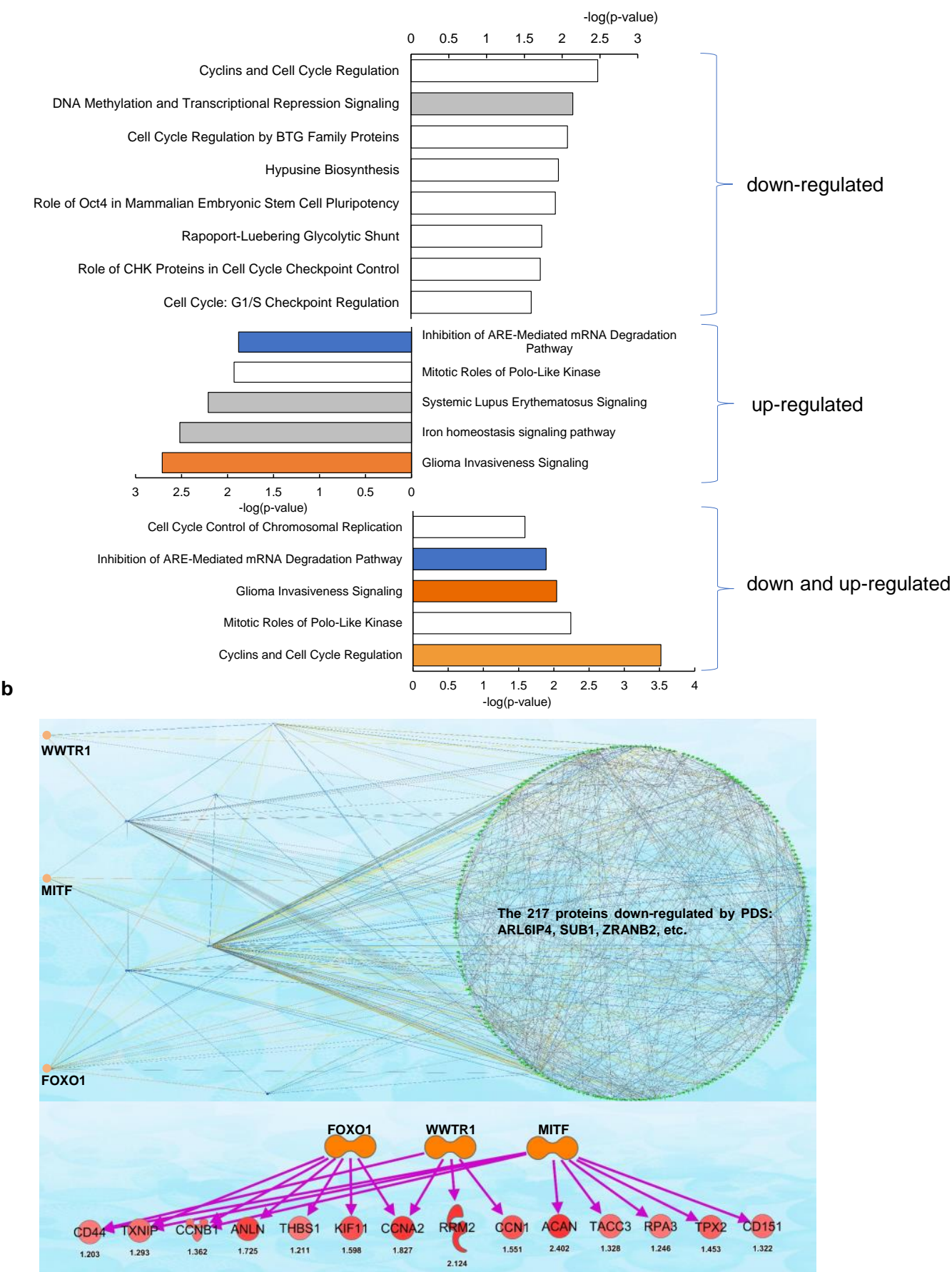

Figure 3. Bioinformatics analysis of differentially expressed proteins due to PDS treatment. (a) The canonical pathways with which PDS-regulated proteins with FC < 1.2 (down-regulated), $\mathrm{FC}>1.2$ (up-regulated) and $|\mathrm{FC}|>1.2$ (down and up-regulated) are associated, respectively. Statistically significant canonical pathways are ranked according to their $p$ values $(-\log p)$. (b) The molecule activity predictor (MAP) simulation of 217 PDS down-regulated proteins (green dots) with $\mathrm{FC}<1$ performed by IPA. It shows that the down-regulated proteins lead to the activation of three 
transcription factors: WWTR1, MITF and FOXO1, which subsequently up-regulate the downstream proteins listed in the bottom with MS-detected fold-changes below.

\section{PDS promotes cytotoxicity of trans-PtTz by silencing $S U B 1$}

It is notable that among the PDS down-regulated genes we identified, SUB1, which expresses the human positive cofactor (PC4), had the second highest foldchange (4.76) (Figure 2c), evidenced further by Western Blot assay which showed that $10 \mu \mathrm{M}$ PDS almost silenced this gene completely (Figure 4a). Endogenous PC4 is an abundant single-strand DNA binding protein that stimulates activator-dependent class II gene transcription. It specifically recognizes G4 structure and DNA lesions, ${ }^{27-}$ ${ }^{30}$ thereby activates double-strand break (DSB) repair by stimulating the joining of non-complementary DNA ends and promotes genome stability. ${ }^{31}$ Our previous study revealed that PC4 recognized and specifically bound to 1,3-intrastrand crosslinked DNA by trans-[ $\mathrm{PtCl}_{2}\left(\mathrm{NH}_{3}\right)$ (thiazole)] (trans-PtTz), a cytotoxic transplatinum complex $^{32}$ (Figure 1a), and may play a crucial role in cellular response to DNA damage by trans-PtTz. ${ }^{28}$ These together inspired us to investigate how the PDSinduced downregulation of PC4 would impact the cytotoxicity of trans-PtTz which is believed to target genomic DNA as an anticancer agent. ${ }^{33}$

Firstly, we measured the $\mathrm{IC}_{50}$ of PDS alone towards HeLa cells. As shown in Figure $\mathrm{S} 3$, the $\mathrm{IC}_{50}$ of PDS was $>100 \mu \mathrm{M}$ for $24 \mathrm{~h}$ treatment, though $10 \mu \mathrm{M}$ PDS could cause $\sim 50 \%$ HeLa cell death when the incubation time was extended to $72 \mathrm{~h}$. This indicates that PDS alone is a low cytotoxic compound. Next, we evaluated the cytotoxicity of trans-PtTz towards HeLa cells when PDS co-existed in the culture media. The results showed that the co-existence of $10 \mu \mathrm{M}$ PDS had little effect on the cytotoxicity of trans-PtTz (Figure S4a). Given the downregulation of PC4 by PDS takes time, we then performed in vitro anti-proliferative assay for trans-PtTz after HeLa cells were pre-treated with PDS for $24 \mathrm{~h}$. The results showed that the $\mathrm{IC}_{50}$ of trans-PtTz was dramatically reduced by 4.2 - and 5.5-fold subject to pre-treatment with 2 and $10 \mu \mathrm{M}$, respectively (Figure $4 \mathrm{~b}$ and Figure S4b). In both cases, the $\mathrm{IC}_{50}$ 
value of trans-PtTz was even slightly lower than that of cisplatin, one of the most widely used chemotherapeutic, of which the $\mathrm{IC}_{50}$ was increased slightly when the HeLa cells were pre-treated with PDS (Figure $4 b$ and Figure S4c), perhaps due to activation of cell cycle process by PDS (vide supra). Notably, there was no obvious difference between the $\mathrm{IC}_{50}$ of trans-PtTz with $2 \mu \mathrm{M}$ and $10 \mu \mathrm{M}$ PDS pre-treatment (Figure $4 \mathrm{~b}$ ). According to the Western Blotting data shown in Figure 4a, $2 \mu \mathrm{M}$ PDS could only knock down ca. 50\% of PC4, we speculate that since PC4 is abundantly expressed in cells, 50\% deletion of PC4 in HeLa cells already reduced the binding of PC4 to damaged DNA by trans-PtTz sufficiently, resulting significant promotion of cytotoxicity of trans-PtTz. This was verified by SUB1 silencing experiment, where a siRNA against PC4 knocked out only ca. $42 \%$ of PC4, but resulted in 2.5 -fold increase in the cytotoxicity of trans-PtTz towards HeLa cells (Figure 4c).

In order to further verify that the promotion of cytotoxicity of trans-PtTz by PDS did resulted from the downregulation of PC4 which might hamper the repair of DNA lesion induced by trans-PtTz, we used time of flight secondary ion mass spectrometry (ToF-SIMS) to image trans-PtTz in HeLa cells, in particular in nuclei rendered by $\mathrm{PO}_{3}{ }^{-}$ions ${ }^{34}$, with and without PDS pretreatment. The cells were divided into three groups: blank group (cells were cultivated in the absence of both PDS and trans-PtTz), control group (cells were treated with $25 \mu \mathrm{M}$ trans-PtTz only for 24h) and PDS group (cells were pretreated with $10 \mu \mathrm{M}$ PDS for $24 \mathrm{~h}$ and then exposed to $25 \mu \mathrm{M}$ transPtTz for another $24 \mathrm{~h}$ ). The resulting images showed that the platinum content as indicated by $[\mathrm{PtCN}]^{-34,35}$ at the signal cell level was higher in the PDS pre-treated cells than in the control group of cells (Figure 5). The statistical results of randomly selected 20 cells in PDS group and PDS group also showed that platinum accumulation in the cells pre-treated by PDS was significantly higher than that in the control group of cells (Figure 5c), confirming that the pretreatment of PDS increased the accumulation of trans-PtTz in HeLa cells, subsequently promoting the cytotoxicity of trans-PtTz, most probably ascribed to reduction in the repair of platinated DNA via knocking down PC4 expression. Moreover, the ICP-MS 
measurement of $\mathrm{Pt}$ content in genomic DNA of large scale of HeLa cells demonstrated that the Pt content binding to DNA in HeLa cells pre-treated with PDS was 4-fold higher than that binding to DNA in the control cells (Figure 4d), further confirming that PDS pretreatment increased platination of DNA in HeLa cells, thereby promoting the cytotoxicity of trans-PtTz. 
a

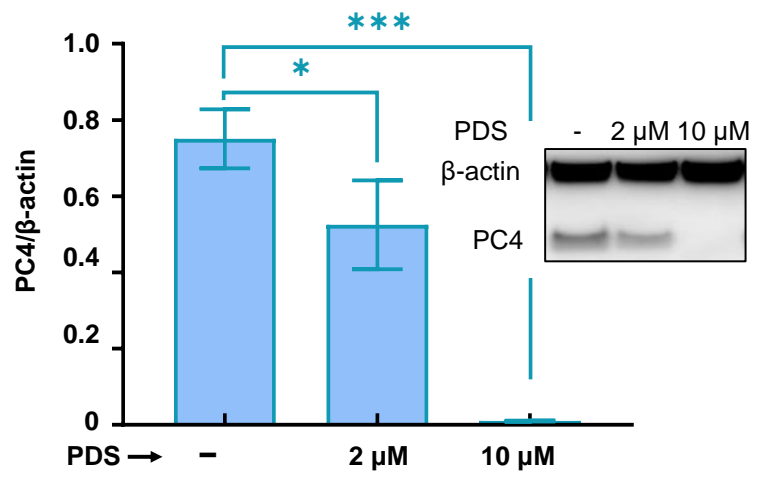

b

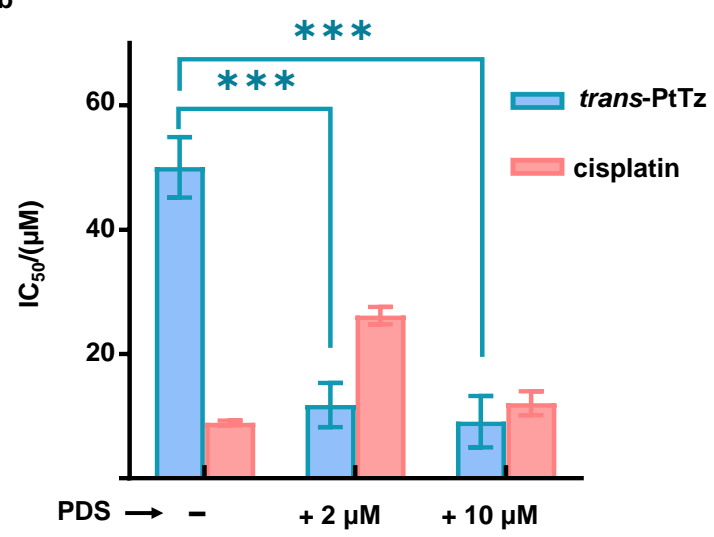

c

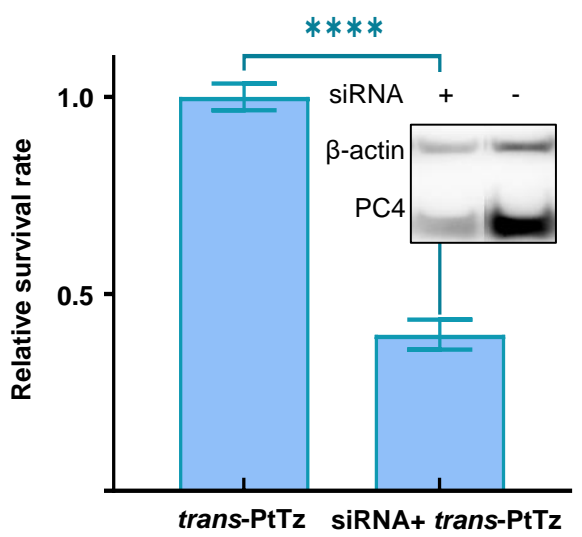

d

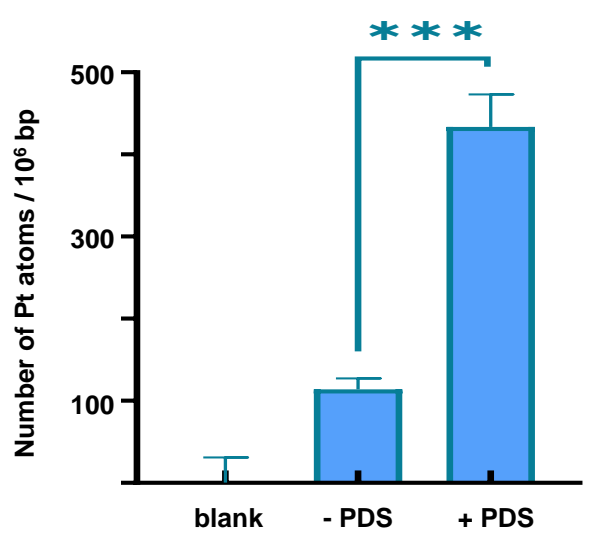

Figure 4. (a) Ratio of PC4 to the internal standard protein $\beta$-actin in HeLa cells without and with PDS pre-treatment measured by Western Blot assay $(n=3)$. The insert shows the optical density of PC4 and $\beta$-actin in a WB measurement. (b) IC50 values of trans-PtTz (blue) and cisplatin (red) towards HeLa cells without and with PDS pre-treatment $(n=3)$. (c) Relative survival rates of HeLa cells, of which PC4 was knocked down by siRNA, treated with $25 \mu \mathrm{M}$ trans-PtTz for $24 \mathrm{~h}(\mathrm{n}=6)$. The HeLa cells treated with the transfection agents (Lipofectamine RNAiMAX) alone were used as a control. The insert shows the optical density of PC4 and $\beta$-actin in a WB measurement. (d) The number of Pt atoms bound to 106 base pair measured by ICPMS $(n=3)$ in HeLa cells treatment with $25 \mu \mathrm{M}$ trans-PtTz with and without pretreatment of $10 \mu \mathrm{M}$ PDS. The blank represents the aqueous solution containing all reagents to prepare the samples but no DNA extract. Two-tailed unpaired Students'ttest was used for all statistics analysis, * indicates $\mathrm{p}<0.05, * * * \mathrm{p}<0.001$, and $* * * * \mathrm{p}$ $<0.0001$. 

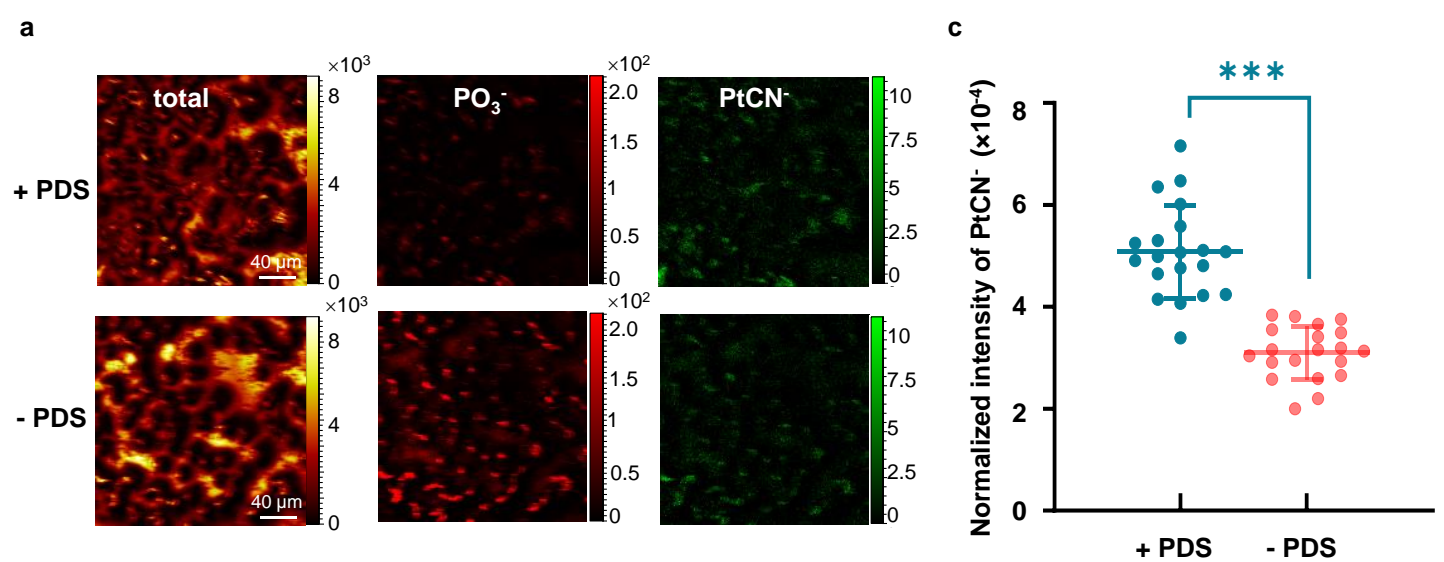

b

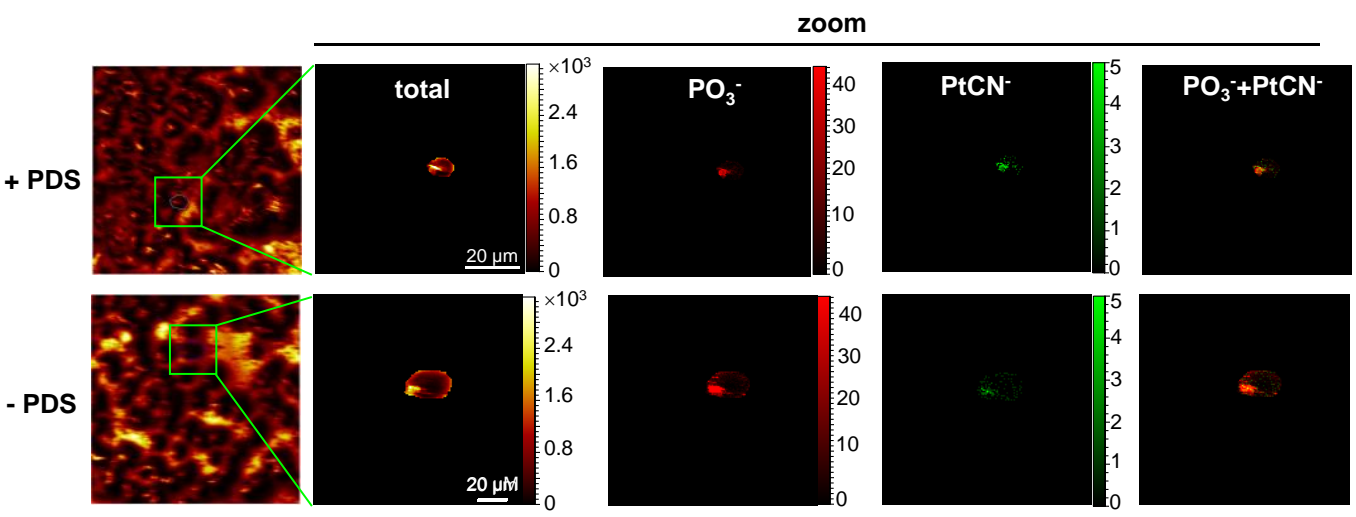

Figure 5. ToF-SIMS images of HeLa cells exposed to $25 \mu \mathrm{M}$ trans-PtTz for $24 \mathrm{~h}$ without PDS pre-treatment (-PDS), or with $10 \mu \mathrm{M}$ PDS pre-treatment (+PDS) for 24 h. (a, b) Images of total ions, PO3- and PtCN- in a $250 \times 250 \mu \mathrm{m}$ of view (a) and in a single cell. (c) The normalized intensity of PtCN- signal determined by ToF-SIMS in each HeLa cell. We randomly selected 20 cells in each group for statistic calculation.

\section{Discussion}

As mentioned earlier, PDS acting as a G4 inducer and/or stabilizer is expected to target the genes containing rich G4 potential sequences. Our study herein confirmed that all the target genes of PDS indeed have a large number of G4 forming G-rich sequences (QGRS) in their full gene sequences and promotor sequences. However, the number of QGRS is not directly proportional to the reduction in protein expression by PDS, because the location of PDS targeting site, e.g. promoter region, 
impacts gene expression more than the number of targeting sites.

On the other hand, although most of PDS downregulated proteins with FC>1.5 are RNA binding proteins, they were not enriched in certain signaling pathways. This may be ascribed to that that the genes recognized and targeted by PDS are sequencespecific rather than function-specific. When we annotated the down- and up-regulated proteins together, we found that PDS restrains the inhibition of ARE-mediated mRNA degradation pathway, and activates the glioma invasiveness signaling, and the cyclins and cell cycle regulation pathways. The activation of the glioma invasiveness signaling implies that PDS may promote the development and metastasis of glioma. The AU-rich element (ARE) located at the 3'-UTR of many gene transcripts governs the decay rates of the mRNA, thereby regulated the expression of these genes. ${ }^{36}$ The hampering of the inhibition of ARE-mediated mRNA degradation pathway by PDS may disturb the fine control of mRNA turnover in cells, resulting in abnormal gene regulation. What's more, among the genes regulated by PDS, we have hardly found downregulation of oncogenes and upregulation of tumor suppressor genes. With regard to these evidences, PDS alone seems not to be a potential anticancer agent via inducing and/or stabilizing G4 structures in oncogenes, at least in HeLa cells.

The high anticancer efficiency of cisplatin and the clinical ineffectiveness of its trans-isomer (transplatin) are considered to be a paradigm of the classic structureactivity relationship of small molecular chemical drugs. However, when one of the amine ligands in transplatin is replaced by a planar amine (L), the transplatinum complexes in type of trans-[ $\left.\mathrm{PtCl}_{2}\left(\mathrm{NH}_{3}\right)(\mathrm{L})\right]$ become cytotoxic, and even have activity against cisplatin-resistant tumor cells. ${ }^{37,38}$ Trans- $\left[\mathrm{PtCl}_{2}\left(\mathrm{NH}_{3}\right)\right.$ (thiazole)] (trans-PtTz) is such a complex, but its cytotoxicity is still much lower than that of cisplatin. Like cisplatin, trans-PtTz was believed to target DNA. However, unlike cisplatin which forms mainly 1,2-intrastrand crosslinked DNA adducts, trans-PtTz produces monofunctional (30-40\%), 1,3-intrastrand crosslinked (20-40\%) and 1,2-interstrand crosslinked DAN adducts (30-40\%). ${ }^{33}$ Unfortunately, which form of DNA damage induced by trans-PtTz plays a major role in its cytotoxicity has remained unclear. 
Our previous work revealed that the human nuclear positive cofactor PC4 recognized and specifically bound to 1,3-intrastrand crosslinked DNA by transPtTz. ${ }^{28}$ However, the biological implication and consequence of the unique recognition and interaction between PC4 and 1,3-trans-PtTz crosslinked DNA have not been deciphered so far. PC4 is an abundant multifunctional nuclear protein, and plays important roles in various cellular processes such as transcription, DNA repair and replication, chromatin organization and cell cycle progression. ${ }^{39-43}$ PC4 usually forms a homodimer to host single-stranded DNA (ssDNA) at DNA damage sites, recruiting various proteins, in particular DNA repair proteins, to exert their functions. ${ }^{44-46}$ Our studies herein unambiguously unraveled that the PDS induced downregulation of PC4 promoted the cytotoxicity of trans-PtTz via retarding the PC4-mediated repair of the DNA lesion induced by trans-PtTz. In the other words, PC4 binds to the transplatinated DNA to trigger DNA repair, which as a consequence reduces the cytotoxicity of trans-PtTz.

Given that cisplatin mainly causes 1,2-intrastrand cross-linked DNA lesion, leading to cell death and apoptosis, ${ }^{47}$ trans-PtTz, which causes DNA damages by forming 1,3-intranstrand/1,2-interatrand DNA adducts and monofunctional DNA adducts, was showed to have no cross-resistance with cisplatin. ${ }^{37,}{ }^{38}$ However, the low cytotoxicity of trans-PtTz limits its further application. With regard to this, the significantly promotion of cytotoxicity of trans-PtTz by PDS provides a unique solution to circumvent resistance against cisplatin which is a major restraint for cisplatin use in clinic. Our study herein also implicates a new strategy for the rational design of novel multi-targeting platinum anticancer drugs via conjugating PDS as a ligand to the coordination scaffold of transplatin or encapsulating trans-PtTz and PDS into a controllably released drug carrier system.

\section{Conclusions}

In summary, in the present work we discovered for the first time that the G4 
stabilizer and inducer, PDS, remarkably down-regulated 22 proteins in HeLa cells by targeting their genes, in turn upregulating significantly 16 proteins related to regulation of cell cycle and cellular component organization. Importantly, PDS was demonstrated to downregulate the expression of human positive cofactor PC4, dramatically promoting the cytotoxicity of trans-PtTz towards HeLa cells. Further studies revealed that PDS induced downregulation of PC4 retarded the repair of transPtTz induced DNA lesion mediated by PC4, and increased accumulation of transPtTz in cells, thereby enhancing the cytotoxicity of this complex. This finding presents a novel strategy for designing new multi-targeting platinum anticancer drugs to battle drug resistance to cisplatin.

\section{Experimental}

\section{Chemicals and Materials}

Dithiothreitol (DTT) and Iodoacetamide (IAA) were purchased from J\&K CHEMICA (China). Triethylammonium Bicarbonate and TMT10plex ${ }^{\mathrm{TM}}$ Isobaric Label Reagent Set were obtained from Thermo Scientific ${ }^{\mathrm{TM}}$. MS grade Acetonitrile and water were purchased from Fisher Chemical. Total Protein Extraction Kit was obtained from BestBio and Enhanced BCA protein assay kit was from Beyotime. For antibodies, except BG4 (Ab00174-1.1) was purchased from Absolute Antibody Ltd, all other antibodies were purchased from Abcam. Cell Counting Kit-8 (CCK-8) was purchased from MedChemExpress.

\section{Cell culture}

Human HeLa cervical cancer cells (National Infrastructure of Cell Line Resource, Beijing, China) were cultured in DMEM (Dulbecco's Modifed Eagle's Medium, Gibco), which contained 10\% fetal bovine serum (FBS, Gibco) and 1\% penicillinstreptomycin (GE Heathcare Life Sciences). All cells were cultured in 5\% CO2 in a $37^{\circ} \mathrm{C}$ incubator.

\section{Laser scanning confocal microscopy fluorescence imaging}

To localize PDS-induced G4s in cells, we applied Cas9-SunTag technique to image 
telomeres while applying G-quadruplex antibodies $B G 4^{24}$ to visualize $\mathrm{G} 4 \mathrm{~s}$, including DNA/RNA G4s, by laser scanning confocal microscopy (LSCM) fluorescence imaging. Cas9-SunTag is one of fluorescence probes for labeling specific DNA sequences or gene loci in living cells. ${ }^{23}$ It links 24 polypeptide scaffolds at the Cterminus of dCas9 protein, allowing dCas9 to recruit 24 sfGFP proteins into the hybridization sites of sgRNA and genomic DNA so as to enhance significantly fluorescence signal of DNA targets. However, we found that the GFP fluorescence signal derived from dCas9-SunTag at telomere regions was largely quenched due to G4-BG4 immunostaining. ${ }^{48}$ Thus, we used immunostaining to illuminate telomeres via HA-tag expressed by the HA-tagged scfv-GCN4-GFP-VP64 plasmid. ${ }^{23}$ In this case, the superposition of the antibody to BG4 and the antibody to the HA-tag can be used to judge whether and how much G4s co-localize with telomeres.

To achieve the co-localization imaging, HeLa cells were seeded in confocal dish (ThermoFisher Scientific) and grew in DMEM in 5\% CO2 in a $37{ }^{\circ} \mathrm{C}$ incubator. When the cell density reached about 70\%, the dCas9-SunTag10×-v4, scfv-GCN4GFP-VP64 and sgTelo plasmids, which were kindly provided by Professor Yu Zhang at National Institute of Biological Sciences as gifts, were simultaneously transfected with Lipo3000 transfection reagent (ThermoFisher Scientific). After 48 h, the cells were treated with cold methanol-acetic acid fixative for $10 \mathrm{~min}$, washed three times with phosphate-buffered saline (PBS), permeabilized with $0.1 \%$ Triton-X100/PBS on the decolorizing shaker for $30 \mathrm{~min}$ and then blocked with 5\% BSA/PBS solution at $37{ }^{\circ} \mathrm{C}$ for $1 \mathrm{~h}$. Thereafter, the cells were incubated with the rabbit polyclonal primary antibody to HA tag (Abcam, ab9110) and the G4 primary antibody BG4 (Absolute Antibody Ltd, Ab00174-1.1) at $37{ }^{\circ} \mathrm{C}$ for $1 \mathrm{~h}$, washed 5 times with buffer $(0.2 \%$ BSA/PBS), then incubated with the donkey anti-rabbit secondary antibody conjugated with Alexa Fluor 488 (Abcam, ab150073) to ab9110 and the goat anti-mouse secondary antibody conjugated with Cy5 (ab136127) to ab150073 at $37{ }^{\circ} \mathrm{C}$ for $1 \mathrm{~h}$, followed by washing three times with buffer prior to LSCM imaging. The excitation and emission wavelength were $488 \mathrm{~nm}$ and $500-600 \mathrm{~nm}, 635 \mathrm{~nm}$ and $650-750 \mathrm{~nm}$ 
for Alexa Fluor®488 and Cy5, respectively.

\section{Quantitative proteomics analysis}

Protein extraction. HeLa cells culturing in DMEM as described above were divided into control group and PDS treated group, and incubated in the absence and the presence of $10 \mu \mathrm{M}$ PDS, respectively, at $37{ }^{\circ} \mathrm{C}$ for $24 \mathrm{~h}$. The cells were then individually harvested, lysed on ice and extracted whole cell proteins by total protein extraction kit (BestBio). The concentration of raw protein extracts was measured by BCA Kit (Beyotime).

Protein digestion. Exactly $300 \mu \mathrm{g}$ extracted proteins in lysis buffer from each group was transferred to $1.5 \mathrm{~mL}$ low protein binding microcentrifuge tube (Thermo Fisher Scientific), and DTT was added at a final concentration of $5 \mathrm{mM}$. The resulting mixture reacted at $37{ }^{\circ} \mathrm{C}$ for $1 \mathrm{~h}$. Then IAA was added at a final concentration of 10 $\mathrm{mM}$ to alkylate the cyteine residues by incubation at $25{ }^{\circ} \mathrm{C}$ for $45 \mathrm{~min}$ in the dark. After diluted 3 times with $50 \mathrm{mM}$ Tris- $\mathrm{HCl}(\mathrm{pH} 8.0), 6 \mu \mathrm{L} 1 \mu \mathrm{g} / \mu \mathrm{L}$ trypsin was added to digest proteins at $25{ }^{\circ} \mathrm{C}$ overnight. Thereafter, the peptides were desalted in $\mathrm{C} 18$ cartridge (Waters Sep-Pak part No. WAT023590). The C18 column was firstly activated by $1 \mathrm{~mL}$ acetonitrile (ACN) and $1 \mathrm{~mL} \mathrm{50 \% (vol/vol)} \mathrm{ACN} / \mathrm{H}_{2} \mathrm{O}$ with $0.1 \%$ ( $\mathrm{vol} / \mathrm{vol}$ ) formic acid (FA) successively, followed by equilibration with $3 \mathrm{~mL}$ of $0.1 \%$ (vol/vol) TFA (trifluoacetic acid) in $\mathrm{H}_{2} \mathrm{O}$. Then the peptides were loaded to the $\mathrm{C} 18$ column, and the desalting was achieved by washing the column with $3 \mathrm{~mL} 0.1 \%$ ( $\mathrm{vol} / \mathrm{vol})$ TFA and $1 \mathrm{~mL}$ of $1 \%$ (vol/vol) FA. The peptide residues were sequentially eluted by $1 \mathrm{~mL} 50 \%$ (vol/vol) $\mathrm{ACN}$ and $1 \mathrm{~mL} 80 \%$ (vol/vol) $\mathrm{ACN} / \mathrm{H}_{2} \mathrm{O}$, and the eluations were merged, followed by drying in vacuum centrifuge (CentriVap, ThermoFisher Scientific).

Stable isotopic labeling. Exactly $100 \mu \mathrm{g}$ peptide residues of each group was redissolved in $50 \mathrm{mM}$ HEPES ( $\mathrm{pH} 8.5$ ) to a final concentration of $1 \mu \mathrm{g} / \mu \mathrm{L}$ and labeled with TMT labeling reagent (Thermo Fisher Scientific). The sample of the control group was labeled with $130 \mathrm{~N}$, and the PDS group was labeled with 129C. The labeling reaction was initialized by incubation at room temperature for $1 \mathrm{~h}$ and 
quenched by $8 \mu \mathrm{L}$ of $5 \%$ hydroxylamine. The labeled peptides derived from control group and PDS group were then equivalently mixed, desalted and dried as described above.

HPLC pre-fractionation. The labeled peptide mixture was re-dissolved in $100 \mu \mathrm{L} 2 \%$ ( $\mathrm{vol} / \mathrm{vol}$ ) $\mathrm{ACN} / \mathrm{H}_{2} \mathrm{O}$ containing $4.5 \mathrm{mM}$ ammonium formate $(\mathrm{pH} 10)$ for basic reversephase chromatography pre-fractionation. Aliquot $(97 \mu \mathrm{L})$ of peptide mixture was load to HPLC (Agilent Technologies 1260 infinity) with Agilent ZORBAX 300 ExtendC18 column. The mobile phase A was $4.5 \mathrm{mM}$ ammonium formate in $2 \%$ (vol/vol) $\mathrm{ACN} / \mathrm{H}_{2} \mathrm{O}(\mathrm{pH} 10)$, and phase $\mathrm{B} 4.5 \mathrm{mM}$ ammonium formate in $90 \%$ (vol/vol) $\mathrm{ACN} / \mathrm{H}_{2} \mathrm{O}(\mathrm{pH}$ 10). The gradient started with $0 \% \mathrm{~B}$ until 7 min and continuously increased to $16 \% \mathrm{~B}$ at $13 \mathrm{~min}, 40 \% \mathrm{~B}$ at $73 \mathrm{~min}, 44 \% \mathrm{~B}$ at $77 \mathrm{~min}$, and $60 \% \mathrm{~B}$ at 82 min and kept until $96 \mathrm{~min}$, then increase to $90 \% \mathrm{~B}$ at $100 \mathrm{~min}$. The flow rate was 1 $\mathrm{mL} / \mathrm{min}$. The fractions were collected chronologically into twelve tubes from $3 \mathrm{~min}$ to 96 min, lyophilized and re-dissolved with $\mathrm{H}_{2} \mathrm{O}$ containing $0.1 \%$ FA to a $500 \mathrm{ng} / \mu \mathrm{L}$ concentration for mass spectrometric analysis.

NanoLC-MS/MS analysis. Mass spectrometric quantification was performed on an Orbitrap Fusion Lumos mass spectrometer coupled with an EASY-nLC 1200 nanoUPLC system equipped with an Acclaim ${ }^{\mathrm{TM}}$ PepMap $^{\mathrm{TM}} 100$ pre-column $(20 \mathrm{~mm} \times$ $75 \mu \mathrm{m}, 3 \mu \mathrm{m})$ and an Acclaim ${ }^{\mathrm{TM}}$ PepMap ${ }^{\mathrm{TM}}$ RSLC C18 analytical column $(150 \mathrm{~mm} \times$ $75 \mu \mathrm{m}, 2 \mu \mathrm{m})$. The UPLC mobile phase A was water containing $0.1 \% \mathrm{FA}$, and phase B $80 \%$ (vol/vol) methanol/water containing $0.1 \%$ FA. The UPLC gradient started with $2 \% \mathrm{~B}$ and increased to $7 \%$ at $7 \mathrm{~min}$, then to $20 \%$ at $69 \mathrm{~min}, 35 \%$ at $90 \mathrm{~min}$ and sharply to $95 \%$ within $5 \mathrm{~min}$, remained for $4 \mathrm{~min}$, and finally decreased to $2 \%$ within 8 min and remained for 3 min. Aliquot $(1 \mu \mathrm{L})$ of each HPLC fraction described above was injected to UPLC, and the elution from the analytical column was directly infused to the mass spectrometer for MS/MS analysis. The detail of the parameters of the MS/MS analysis are listed in Table S4.

Protein identification and quantification. Raw MS/MS data were searched in Proteome Discoverer (Thermo Scientific, version 2.3) database for peptide and 
protein identification. Sequest HT search engine was used for peptide-spectrum matching (PSM). The dynamic modifications were oxidation at methionine, methylation at lysine, glutarnine and arginine, acetylation at lysine and serine, phosphorylation at serine, threonine and tyrosine, and TMT labeling at lysine. The static modifications were carbamidomethylation at cysteine and TMT labeling at Nterminus of peptides. The quantitative results were normalized based on the total peptide amount in each group. Only proteins identified with false discovery rate (FDR) lower than $0.01, p$-value lower than 0.05 and abundance ratio lower than 0.833 or larger than 1.20 were included for further analyses.

The entire quantitative proteomics analysis was carried out in three independent replicates.

\section{Bioinformatics analysis}

The proteins with fold-change $>1.2$ (equal to abundance ratio of PDS group vs control group) or $<-1.2$ (equal to the negative reciprocal of abundance ratio of PDS group vs control group) were input to the data pool of Ingenuity Pathway Analysis (IPA) program (QIAGEN Digital Insights) ${ }^{49}$ for bioinformatics analysis, which included canonical pathways, upstream analysis, diseases and function analysis, etc.

\section{Western Blot assay}

The influence on the expression level of PC4 in HeLa cells by PDS were measured by Western Blotting with $\beta$-actin as an internal control protein. HeLa cells were cultivated in $2 \mu \mathrm{M}, 10 \mu \mathrm{M}$ and the absence of PDS, respectively, for $24 \mathrm{~h}$. The cells were harvested for extracting whole cell proteins using Mammalian protein extraction reagent (Thermo Scientific). Then the BCA assay was performed to determine the concentration of each protein extraction. The aliquot $(60 \mu \mathrm{g})$ of protein was boiled at $95{ }^{\circ} \mathrm{C}$ for 5 min with the gel-loading buffer (4xLDS, Genscript, Nanjing, China), and separated with a $10 \%$ gradient SDS-PAGE gel (Genscript) at $110 \mathrm{~V}$ for $40 \mathrm{~min}$. Then the separated proteins were transferred to a PVDF membrane (Millipore, $0.2 \mu \mathrm{m}$ ). The membrane was blocked in 5\% nonfat dry milk (Biofroxx) dissolved in 0.1\% TBST at room temperature for $1 \mathrm{~h}$, followed by incubated with primary antibodies (Abcam, 
ab8227, ab72132) in appropriate dilutions for $1 \mathrm{~h}$, washed by blocking buffer for 30 min, incubated with the secondary antibody (Abcam, ab7090) for $1 \mathrm{~h}$, washed as described before and washed with $0.1 \%$ TBST for $5 \mathrm{~min}$. The protein bands were visualized by chemiluminescent HRP substrate (Millipore), and the optical densities were determined by Image $\mathrm{J}$.

\section{Time of flight secondary ion mass spectrometry (ToF-SIMS) imaging}

For ToF-SIMS imaging, HeLa cervical cancer cells were seeded on silicon wafer and cultivated to a density of $80 \%$ and divided into three groups: blank group (cells were cultivated without both PDS and trans-PtTz), control group (cells were treated with $25 \mu \mathrm{M}$ trans-PtTz for $24 \mathrm{~h}$ ) and PDS group (cells were pretreated with $10 \mu \mathrm{M}$ PDS for $24 \mathrm{~h}$ and then treated with $25 \mu \mathrm{M}$ trans-PtTz for another $24 \mathrm{~h}$ ). The cells were fixed with pure pre-cooled ethanol for $20 \mathrm{~min}$, then washed three times with PDS, followed by washing three times with ammonium acetate $(150 \mathrm{mM}, \mathrm{pH}=7.4)$, then quickly freezed by liquid $\mathrm{N}_{2}$ and transferred intermediately into a lyophilized (LGJ-12, Beijing Songyuanhuaxing Technology Develop Co., Ltd) at $193 \mathrm{~K}$ to $208 \mathrm{~K}$ for freeze-drying overnight.

ToF-SIMS imaging was carried out with a ToF-SIMS 5 instrument (ION-ToF GmbH, Münster, Germany) equipped with a $30 \mathrm{keV}$ liquid metal primary ion source. The high-lateral-resolution (ca. $200-300 \mathrm{~nm}$ ) images of cells were recorded using $\mathrm{Bi}^{3+}$ primary ion gun. For imaging, signal was collected with $256 \times 256$ pixels in negative mode and the area was $250 \mu \mathrm{m} \times 250 \mu \mathrm{m}$. The scan times of each sample were exactly 3000 to obtain high quality images. The images of various ions were collected and plotted with the Surface Lab software (version 6.4 ION-ToF GmbH). The mass to charge ratio $(\mathrm{m} / \mathrm{z})$ was calibrated using the signals of $\mathrm{C}^{-}, \mathrm{CH}^{-}, \mathrm{CH}^{2-}, \mathrm{C}^{2-}, \mathrm{C}_{2} \mathrm{H}^{-}$. The

image of $\mathrm{Pt}$ was constructed by sum of signals of $\left[{ }^{194} \mathrm{PtCN}\right]^{-},\left[{ }^{195} \mathrm{PtCN}\right]^{-}$and $\left[{ }^{196} \mathrm{PtCN}\right]^{-}$ions and the image of total and $\mathrm{PO}_{3}{ }^{-}$was used to profile the shape of cells. Shift correction was applied by the software for all the images. Region of interest (ROI) were created for 20 cells in each sample. The Pt signal was normalized to total signal for further statistics. 


\section{Inductively coupled plasma mass spectrometry (ICP-MS)}

For ICP-MS analysis, HeLa cells were cultured in DMEM as described above and the group set was the same as ToF-SIMS imaging. Cells were collected in each group and DNA was extracted by Genomic DNA Mini Preparation Kit with Spin Column (Beyotime). The concentration of DNA in each sample was detected by NanoDrop (ThermoFisher Scientific) before the concentration of Pt was detected by ICP-MS (Agilent 7700). The experiment was repeated three times independently. The Pt concentrations of control group and PDS group were deducted the background in blank group. Then the numbers of Pt atoms in $10^{6} \mathrm{bp}$ (base pair) in each group were calculated.

\section{In vitro anti-proliferative assay}

For the measurement of cytotoxicity of trans-[ $\mathrm{PtCl}_{2}\left(\mathrm{NH}_{3}\right)$ (thiazole)] (tran-PtTz) with or without PDS pre-treatment of cells, HeLa cells were cultured as described above, and seeded into and grew in a 96 well plate at $37{ }^{\circ} \mathrm{C}$ to achieve $80-90 \%$ density in DMEM medium in the absence of PDS and in the presence of $2 \mu \mathrm{M}$ or $10 \mu \mathrm{M}$ of PDS, respectively. After cultured for $24 \mathrm{~h}$, the cells were wished twice with PBS, and 200 $\mu \mathrm{L}$ medium containing $0,2,8,30,50,70,100,180$ or $200 \mu \mathrm{M}$ of tran-PtTz was added to each well. After $24 \mathrm{~h}$ of incubation at $37{ }^{\circ} \mathrm{C}$, each well was added $10 \mu \mathrm{L}$ CCK-8 (MedChemExpress) reagents and incubated for further $3 \mathrm{~h}$. Then, the absorbance at $450 \mathrm{~nm}$ was measured and the $\mathrm{IC}_{50}$ value, which is the concentration of tested complex inhibiting 50\% growth of cells, were calculated accordingly.

For comparison, the $24 \mathrm{~h} \mathrm{IC}_{50}$ values against HeLa cells of cisplatin, which is the structural isoform of transplatin and one of the widely used anticancer metallodrugs for treatment of solid tumors, in the absence and in the presence of $2 \mu \mathrm{M}$ or $10 \mu \mathrm{M}$ of PDS were measured following the similar procedure described above. The concentration gradient of cisplatin was $0,1,10,15,20,30,50,70$ and $100 \mu \mathrm{M}$. Meanwhile, the $24 \mathrm{~h} \mathrm{IC} 50$ value of PDS alone towards HeLa cells was also determined with a concentration gradient of $0,2,10,20,30,40,50,60,70,100,120,180$ and 200 $\mu \mathrm{M}$. 


\section{SiRNA-mediated $S U B 1$ silencing}

Three siRNA were purchased from Sangon Biotech (Shanghai). The sequences were siRNA1: 5'-GUACGUUAGUGUUCGCGAUUUTT-3'; $\quad$ siRNA2: 5 'ACAUUGAUGAUGCAGUAAGAATT-3'; SiRNA3: 5'UAGAGAAUAUUGGAUGGAUUCTT-3', respectively. HeLa cells were seed into six-hole plates to reach a density to $70 \%$, then the siRNAs were transfected respectively into the cells. The cells with only transfection reagent (Lipofectamine RNAiMAX, Thermo Fisher Scientific) were set as control group. After $48 \mathrm{~h}$ cultivation, the cells were collected and the whole proteins were extracted as described before. Then the Western blot assay was performed to determine the knockdown level of PC4 to choose the siRNA used in the following experiment. The internal control protein was $\beta$-actin.

After selecting the appropriate siRNA, HeLa cells were seeded in the 96-hole plate. The cells were divided into two groups: control group and experiment group. After the cell density reached $70 \%$, the selected siRNA was transfected to the experiment group, while the same amount of Lipofectamine RNAiMAX was added to the control group. After $48 \mathrm{~h}$ of cell culture, both groups of the cells were treated with $25 \mu \mathrm{M}$ trans-PtTz for $24 \mathrm{~h}$. Then cell viability in each group were measured by CCK-8 (MedChemExpress) as described above.

\section{Author Contributions}

Y.H. and T.G. (lead), T.F., X.L., L.Q., Y.Y.Z., F.J., J, H. and S.L. (supporting): data curation, formal analysis; F.W. (lead), S.W., Y.Z. and Y.Y.Z.: funding qacuisition; Q.L. and Y,Z. (equal): project administration; F.W. and Y.H. (lead), Y.Z. and S.W.: writing of original draft and revising.

\section{Conflicts of interest}

\section{Acknowledgements}

We thank the National Natural Science Foundation of China (Grant nos. 21575145, 21927804, 21635008, 21790390 and 21790392) and the National Key Research and Development Program of China (Grant no. 2018YFA0800903) for support. Y.Z. thanks the Youth Innovation Promotion Association of Chinese Academy 
of Sciences (Grant no. 2017051) for support. We thank Professor Yu Zhang at National Institute of Biological Sciences for the Cas9-SunTag plasmids and Professor Yangzhong Liu at University of science and technology of China for trans-PtTz.

\section{Bibliographic references \& notes}

1. R. Hansel-Hertsch, D. Beraldi, S. V. Lensing, G. Marsico, K. Zyner, A. Parry, M. Di Antonio, J. Pike, H. Kimura, M. Narita, D. Tannahill and S. Balasubramanian, Nature Genetics, 2016, 48, 1267-1272.

2. A. Guedin, J. Gros, P. Alberti and J.-L. Mergny, Nucleic Acids Research, 2010, 38, 7858-7868.

3. A. Bedrat, L. Lacroix and J. L. Mergny, Nucleic Acids Research, 2016, 44, 1746-1759.

4. V. S. Chambers, G. Marsico, J. M. Boutell, M. Di Antonio, G. P. Smith and S. Balasubramanian, Nat Biotechnol, 2015, 33, 877-+.

5. R. Hansel-Hertsch, J. Spiegel, G. Marsico, D. Tannahill and S. Balasubramanian, Nat Protoc, 2018, 13, 551-564.

6. S. Cogoi and L. E. Xodo, Nucleic Acids Research, 2006, 34, 2536-2549.

7. A. D. Cox, S. W. Fesik, A. C. Kimmelman, J. Luo and C. J. Der, Nat Rev Drug Discov, 2014, 13, 828-851.

8. T. Miyazaki, Y. Pan, K. Joshi, D. Purohit, B. Hu, H. Demir, S. Mazumder, S. Okabe, T. Yamori, M. Viapiano, K. Shin-ya, H. Seimiya and I. Nakano, Clin Cancer Res, 2012, 18, 1268-1280.

9. C. E. Edling and B. Hallberg, Int J Biochem Cell B, 2007, 39, 1995-1998.

10. G. Radha and S. C. Raghavan, Bba-Rev Cancer, 2017, 1868, 309-314.

11. A. Siddiqui-Jain, C. L. Grand, D. J. Bearss and L. H. Hurley, P Natl Acad Sci USA, 2002, 99, 11593-11598.

12. V. Gonzalez and L. H. Hurley, Annu Rev Pharmacol, 2010, 50, 111-129.

13. R. Rodriguez, S. Muller, J. A. Yeoman, C. Trentesaux, J. F. Riou and S. Balasubramanian, J Am Chem Soc, 2008, 130, 15758-+.

14. W. J. Chung, B. Heddi, F. Hamon, M. P. Teulade-Fichou and A. T. Phan, Angew Chem Int Edit, 2014, 53, 999-1002.

15. A. M. Burger, F. P. Dai, C. M. Schultes, A. P. Reszka, M. J. Moore, J. A. Double and S. Neidle, Cancer Res, 2005, 65, 1489-1496.

16. R. Rodriguez, K. M. Miller, J. V. Forment, C. R. Bradshaw, M. Nikan, S. Britton, T. Oelschlaegel, B. Xhemalce, S. Balasubramanian and S. P. Jackson, Nat Chem Biol, 2012, 8, 301-310.

17. E. Salvati, M. Scarsella, M. Porru, A. Rizzo, S. lachettini, L. Tentori, G. Graziani, M. D'Incalci, M. F. G. Stevens, A. Orlandi, D. Passeri, E. Gilson, G. Zupi, C. Leonetti and A. Biroccio, Oncogene, 2010, 29, 6280-6293.

18. D. Koirala, S. Dhakal, B. Ashbridge, Y. Sannohe, R. Rodriguez, H. Sugiyama, S. Balasubramanian and H. B. Mao, Nat Chem, 2011, 3, 782-787.

19. G. Marsico, V. S. Chambers, A. B. Sahakyan, P. McCauley, J. M. Boutell, M. Di Antonio and S. Balasubramanian, Nucleic Acids Research, 2019, 47, 3862-3874.

20. J. F. Moruno-Manchon, P. Lejault, Y. X. Wang, B. McCauley, P. Honarpisheh, D. A. M. Scheihing, S. Singh, W. W. Dang, N. Kim, A. Urayama, L. Zhu, D. Monchaud, L. D. McCullough and A. S. Tsvetkov, Elife, 2020, 9.

21. J. A. Gilbert, M. J. Blaser, J. G. Caporaso, J. K. Jansson, S. V. Lynch and R. Knight, Nat Med, 2018, 24, 392-400. 
22. L. Ding, M. H. Bailey, E. Porta-Pardo, V. Thorsson, A. Colaprico, D. Bertrand, D. L. Gibbs, A. Weerasinghe, K. L. Huang, C. Tokheim, I. Cortes-Ciriano, R. Jayasinghe, F. Chen, L. H. Yu, S. Sun, C. Olsen, J. Kim, A. M. Taylor, A. D. Cherniack, R. Akbani, C. Suphavilai, N. Nagarajan, J. M. Stuart, G. B. Mills, M. A. Wyczalkowski, B. G. Vincent, C. M. Hutter, J. C. Zenklusen, K. A. Hoadley, M. C. Wendl, L. Shmulevich, A. J. Lazar, D. A. Wheeler, G. Getz and C. G. A. R. Network, Cell, 2018, 173, 305-+.

23. M. E. Tanenbaum, L. A. Gilbert, L. S. Qi, J. S. Weissman and R. D. Vale, Cell, 2014, 159, 635646.

24. G. Biffi, D. Tannahill, J. McCafferty and S. Balasubramanian, Nat Chem, 2013, 5, 182-186.

25. O. Kikin, L. D'Antonio and P. S. Bagga, Nucleic Acids Research, 2006, 34, W676-W682.

26. J. Zimmer, E. M. C. Tacconi, C. Folio, S. Badie, M. Porru, K. Klare, M. Tumiati, E. Markkanen, S. Halder, A. Ryan, S. P. Jackson, K. Ramadan, S. G. Kuznetsov, A. Biroccio, J. E. Sale and M. Tarsounas, Mol Cell, 2016, 61, 449-460.

27. O. Mortusewicz, W. Roth, N. Li, M. C. Cardoso, M. Meisterernst and H. Leonhardt, J Cell Biol, 2008, 183, 769-776.

28. Z. F. Du, Q. Luo, L. P. Yang, T. Bing, X. C. Li, W. Guo, K. Wu, Y. Zhao, S. X. Xiong, D. H. Shangguan and F. Y. Wang, Journal of the American Chemical Society, 2014, 136, 2948-2951.

29. R. B. Caldwell, H. Braselmann, U. Schoetz, S. Heuer, H. Scherthan and H. Zitzelsberger, Sci RepUk, 2016, 6.

30. O. Mortusewicz, B. Evers and T. Helleday, Oncogene, 2016, 35, 761-770.

31. K. Batta, M. Yokokawa, K. Takeyasu and T. K. Kundu, J Mol Biol, 2009, 385, 788-799.

32. U. Bierbach, Y. Qu, T. W. Hambley, J. Peroutka, H. L. Nguyen, M. Doedee and N. Farrell, Inorg. Chem., 1999, 38, 3535-3542.

33. V. Marini, P. Christofis, O. Novakova, J. Kasparkova, N. Farrell and V. Brabec, Nucleic Acids Research, 2005, 33, 5819-5828.

34. F. F. Jia, J. Wang, Y. Zhao, Y. Y. Zhang, Q. Luo, L. Y. Qi, Y. Z. Hou, J. Du and F. Y. Wang, Analytical Chemistry, 2020, 92, 15517-15525.

35. Y. Lin, K. Wu, F. F. Jia, L. Chen, Z. Y. Wang, Y. Y. Zhang, Q. Luo, S. Y. Liu, L. Y. Qi, N. Li, P. Dong, F. Gao, W. Zheng, X. H. Fang, Y. Zhao and F. Y. Wang, Chemical Science, 2021, 12, 5419-5429.

36. S. Vasudevan and S. W. Peltz, Mol Cell, 2001, 7, 1191-1200.

37. V. Brabec, Prog Nucleic Acid Re, 2002, 71, 1-68.

38. J. M. Perez, M. A. Fuertes, C. Alonso and C. Navarro-Ranninger, Crit Rev Oncol Hemat, 2000, 35, 109-120.

39. M. Garavís and O. Calvo, Cur. Gen., 2017, 63, 1023-1035.

40. A. Tavenet, A. Suleau, G. Dubreuil, R. Ferrari, C. Ducrot, M. Michaut, J.-C. Aude, G. Dieci, O. Lefebvre, C. Conesa and J. Acker, Proc. Natl. Acad. Sci. USA, 2009, 106, 14265-14270.

41. Z. Q. Pan, H. Ge, A. A. Amin and J. Hurwitz, J. Biol. Chem., 1996, 271, 22111-22116.

42. J. Y. Wang, A. H. Sarker, P. K. Cooper and M. R. Volker, Mol. Cell. Bio., 2004, 24, 6084-6093.

43. H. Ge and R. G. Roeder, Cell, 1994, 78, 513-523.

44. J. Brandsen, S. Werten, P. C. van der Vliet, M. Meisterernst, J. Kroon and P. Gros, Nat. Struct. Biol., 1997, 4, 900-903.

45. S. Werten and D. Moras, Nat. Struct. Mol. Biol., 2006, 13, 181-182.

46. M. Hyjek-Składanowska, T. A. Vickers, A. Napiórkowska, B. A. Anderson, M. Tanowitz, S. T. Crooke, X.-h. Liang, P. P. Seth and M. Nowotny, J. Am. Chem. Soc., 2020, 142, 7456-7468. 
47. Y. W. Jung and S. J. Lippard, Chem Rev, 2007, 107, 1387-1407.

48. N. Brewis, A. Phelan, J. Webb, J. Drew, G. Elliott and P. O'Hare, J Virol, 2000, 74, 1051-1056.

49. A. Kramer, J. Green, J. Pollard and S. Tugendreich, Bioinformatics, 2014, 30, 523-530. 